\title{
Multi-hole Atrial Septal Defect: A diagnostic and therapeutic challenge
}

\author{
Ricardo Alvarez-Santana ${ }^{1,4}$, Mara Escudero-Salamanca ${ }^{2,4}$, Jesus A Garcia-Diaz $^{3,4}$ and Nilda Espinola-Zavaleta ${ }^{4,5 *}$ \\ ${ }^{1}$ Institute of Medical Sciences. Autonomous University of Ciudad Juarez,Ciudad Juarez- Chihuahua, Mexico \\ ${ }^{2}$ Mexican Faculty of Medicine La Salle University, Mexico City, Mexico \\ ${ }^{3}$ Academic Unit of Medicine. Autonomous University of Nayarit, Tepic-Nayarit, Mexico \\ ${ }^{4}$ Department of Nuclear Cardiology, National Institute of Cardiology Ignacio Chavez, Mexico City, Mexico \\ ${ }^{5}$ Department of Echocardiography, ABC Medical Center I. A. P., Mexico City, Mexico
}

\begin{abstract}
Atrial Septal Defect (ASD) is the third most common congenital heart defect. There are three main types of ASD: ostium secundum, ostium primum and sinus venous. There are few reports of multi-hole ostium secundum ASD, its incidence is estimated in $4-10 \%$.

A 56-year-old male attends to medical consultation due to three-month exertional dyspnea, palpitations and lower limb edema. Transthoracic echocardiogram reported dilatation of right cavities, ostium secundum ASD, severe tricuspid insufficiency, pulmonary hypertension, left ventricular ejection fraction of $60 \%$. A cardiac examination with arrhythmic heart sounds, splitting of the second sound and systolic murmur in second right intercostal space. Electrocardiogram showed atrial fibrillation and incomplete right bundle branch block. The 2D and 3D transesophageal echocardiogram confirmed the presence of multi-hole ostium secundum ASD. Right heart catheterization showed mild pulmonary hypertension. Surgical management was suggested to correct the multi-hole ASD.
\end{abstract}

The diagnosis of the ASD should always include a 3D transesophageal echocardiogram for a detailed assessment of the interatrial septum.

Complex multi-hole ostium secundum ASD is a relative contraindication for closure with an Amplatzer device; therefore, a surgical treatment with opened exposure should be done.

\section{Introduction}

Atrial septal defect (ASD) is the third most common congenital heart disease, with an incidence of 56/ 100,000 births [1]. In Mexico, 12,000-16,000 children are born with congenital heart disease per year, but the exact ASD incidence is not available [2]. On the other hand, congenital heart disease represents the third cause of death in children under five years of age according to the National Institute of Statistics and Geography (INEGI) [3]. There are three main types of ASD: ostium secundum (65 to $75 \%$,), ostium primum $20 \%$ and sinus venosus (5 to 10\%) [1]. There are few reports of multi-hole ostium secundum ASD and its incidence is 4 to $10 \%$ [4]. Currently, the devices made for septal closure are designed for larger defects or nearby multi-hole defects, but when the defects extend beyond the radius of the closure device or there are not all covered, a complete closure is not achieved [4,5].

A male patient in the sixth decade of life, with heart failure symptoms is described. The transesophageal echocardiogram led to the diagnosis of a complex multi-hole ostium secundum ASD that contraindicated the percutaneous treatment.

\section{Clinical Case}

A 56-year-old male attends to medical consultation due to threemonth exertional dyspnea, palpitations and lower limb edema. Transthoracic echocardiogram (TTE) reported dilatation of right cavities, ASD type ostium secundum, severe tricuspid insufficiency (TI), pulmonary hypertension and left ventricular ejection fraction (LVEF) of $60 \%$.
The patient was sent to our institution to continue with the diagnostic studies. At cardiac examination with arrhythmic heart sounds, splitting of the second sound and systolic murmur in the second right intercostal space. The laboratories showed hemoglobin (16 gr/dl) and hematocrit (49\%) both within normal parameters. The electrocardiogram (ECG) with heart rate of $89 \mathrm{bpm}$, atrial fibrillation, and incomplete right bundle branch block. Chest x-ray showed cardiomegaly. The TTE demonstrated ASD with Qp / Qs of 1.9 and dilation of right cavities. Two and three-dimensional transesophageal echocardiogram (TEE) confirmed the presence of a multi-hole ostium secundum ASD, with the presence of at least five defects of different sizes (Figures 1, 2, videos 1 and 2). Right heart catheterization showed mild pulmonary hypertension with pulmonary systolic pressure of 48 $\mathrm{mmHg}$. The patient was no candidate for percutaneous treatment due to the size of the multi-hole ostium secundum ASD and is currently awaiting surgical treatment.

${ }^{\star}$ Correspondence to: Nilda Espinola-Zavaleta, Juan Badiano No 1, Colonia Seccion XVI, Postal Code 14080, Tlalpan, Mexico City, Mexico, Tel: +5255 55732911; E-mail: niesza2001@hotmail.com

Key words: muti-hole atrial septal defect, echocardiography, surgery, amplatzer device

Received: March 15, 2020; Accepted: April 03, 2020; Published: April 08, 2020 


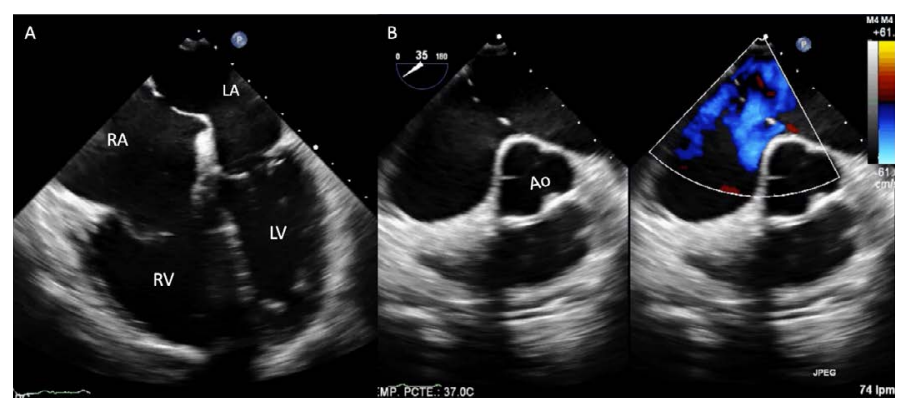

Figure 1. Two-dimensional transesophageal echocardiogram at $0^{\circ}(\mathrm{A})$ and $35^{\circ}$ with color Doppler (B), with a multi-hole ostium secundum atrial septal defect and dilation of the right cavities. Abbreviations: RA-right atrium; RV-right ventricle, LA-left atrium, LV-left ventricle, Ao-aorta

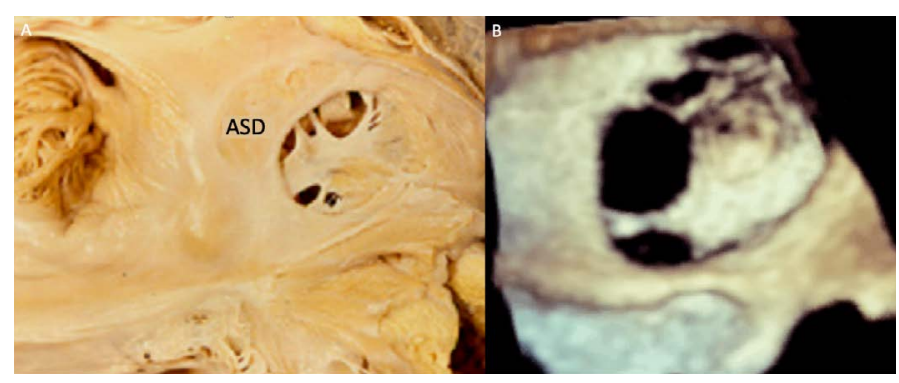

Figure 2. Anatomic-echocardiographic correlation between an equivalent specimen (A) and the three-dimensional transesophageal echocardiogram of the patient (B), showing a multi-hole ASD. Abbreviations: ASD-atrial septal defect

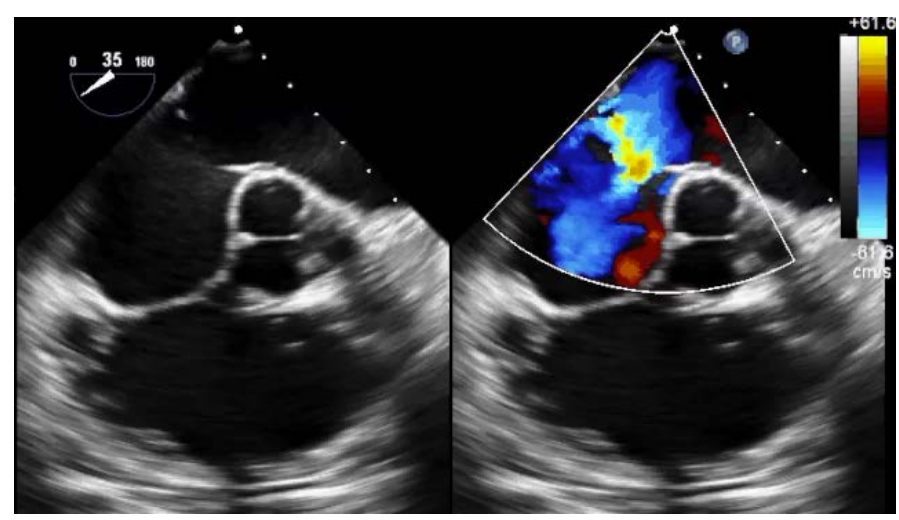

Video 1. Two-dimensional transesophageal echocardiogram with color Doppler, with an ASD with 4 holes

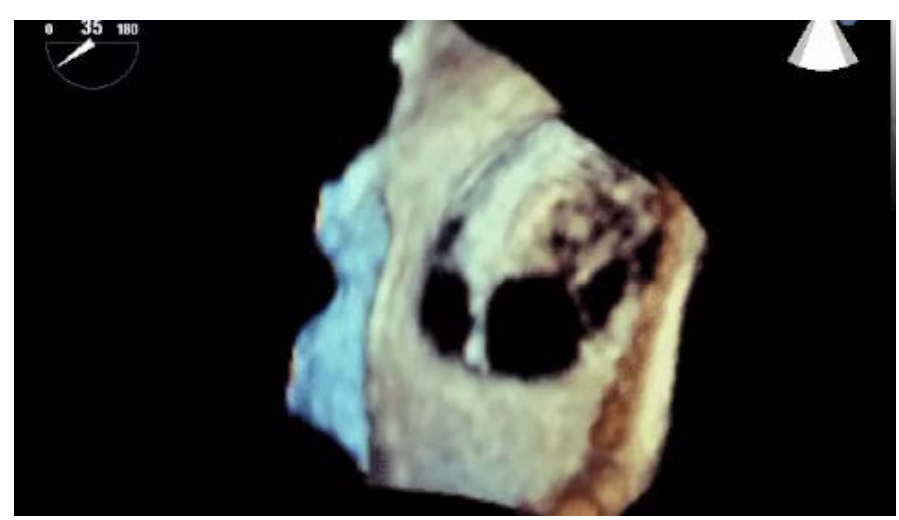

Video 2. Three-dimensional transesophageal echocardiogram with wide ostium secundum ASD with at least 5 holes

\section{Discussion}

It is a very interesting case of a patient in the sixth decade of life, that presented symptoms of heart failure and atrial fibrillation. The TTE showed a wide multi-hole atrial septal defect with significant hemodynamic repercussion characterized by dilatation of the right cavities. The two-dimensional and three-dimensional TEE allowed an accurate assessment of the ASD, which defects were multiple $[6,7]$. Sometimes even with 2D transesophageal echocardiogram, the presence of multiple defects is not identified, which can be observed thru hemodynamic studies [8]. In this way, It is noted that the 3D TEE is superior to the two-dimensional TEE in the evaluation of atrial septal defects, since it allows a complete visualization of the interatrial septum and identifies the presence of additional fenestrations with an excellent correlation with the equivalent specimen, as demonstrated in this case (Figure 2).

Our patient had a multi-hole ostium secundum ASD with at least 5 defects, so he was excluded from percutaneous closure with an Amplatzer device [9]. There are no clinical guidelines in how to close multi-hole ostium secundum ASD, or what therapeutic measure to take in order to make treatment decisions, therefore the closure may result incomplete and the patient may have a residual shunt [10-12]. $\mathrm{He} \mathrm{L}$, et al. made anatomic models with a $3 \mathrm{D}$ printer to analyze the size of the defects and have an adequate closure; this may be a more specific way to assess the therapeutic approach of ASD. However, only one of the five cases they treated presented more than two defects [13].

\section{Conclusion}

The approach of congenital heart disease specifically ostium secundum ASD should always include the performance of $3 \mathrm{D}$ transesophageal echocardiogram for a better visualization of the interatrial septum.

In cases of wide and complex multi-hole ostium secundum ASD, surgical closure is recommended.

\section{Highlights}

- The 3D transesophageal echocardiogram is the technique of choice in the evaluation of ASD because it is the most specific study in comparison with equivalent specimens.

- In complex multi-hole ostium secundum atrial septal defects, treatment must be surgical.

\section{References}

1. Leppert M, Poisson SN, Carroll JD (2016) Atrial Septal Defects and Cardioembolic Strokes. Cardiol Clin 34: 225-230.

2. Varela-Ortiz J, Contreras-Santiago E, Calderon-Colmenero J, Ramirez-Marroquin S, Cervantes-Salazar J, Patiño-Bahena E, et al. (2015) Epidemiologia de pacientes con cardiopatias congenitas sometidos a cirugia en un hospital privado de tercer nivel en Mexico. Rev Invest Med Sur Mex 22: 4

3. INEGI (2015) Instituto Nacional de Estadistica y Geografia. Causas de mortalidad.

4. Farhaj Z (2019) Device closure of diverse layout of multi-hole secundum atrial defect: different techniques and long-term follow-up. Journal of Cardiothoracic Surgery.

5. Schisler T, Subramaniam K (2016) Diagnosis of a Fenestrated Secundum Atrial Septa Defect Detected by Real-Time Three-Dimensional Transesophageal Echocardiography. Journal of Cardiothoracic and Vascular Anesthesia 31: 980-982.

6. Tal R, Dahud Q, Lorber A (2013) Fenestrated Atrial Septal Defect Percutaneously Occluded by a Single Device: Procedural and Financial Considerations. Cardiol Ther 2: $97-102$. 
7. Looney T, Czaja GR, Flanagan MC, Reoma JL, Hulten E (2018) Case of Delayed Diagnosis of Fenestrated Atrial Septal Defect. Circ Cardiovasc Imaging 11: 10.

8. Munin MA, Raggio IM, Faella H (2011) Multi-Fenestrated Atrial Septal Defect: Value of 3D Transesophageal Echocardiography for Diagnosis and Guidance in Percutaneous Closure. Argentine Journal of Cardiology 79: 2.

9. Supomo S, Arjana AZ, Darmawan H (2018) Predictive Model for Secundum Atria Septal Defect Closure with Pulmonary Artery Hypertension in Adult: When to Close. Heart Surg Forum 21: E108-108E111. [Crossref]

10. Masseli J, Bertog S, Stanczak L, Blankenbach K, Majunke N, et al. (2013) Transcatheter closure of multiple interatrial communications. Catheter Cardiovasc Interv 81: 825-836. [Crossref]
11. Yang Y, Xu Z, Jiang S, Zhao S, Zhang G, et al. (2016) Simultaneous Transcatheter Closure of Multiple Atrial Septal Defects Using Dual Amplatzer Septal Occluder Devices. Am J Med Sci 352: 245-251. [Crossref]

12. Cohen M, Armsby L, Burkule N, Fleishman C, Hijazi Z, et al. (2015) Guidelines for the Echocardiographic Assessment of Atrial Septal Defect and Patent Foramen Ovale: From the American Society of Echocardiography and Society for Cardiac Angiography and Interventions. J Am Soc Echocardiogr 28: 910-958.

13. He L, Cheng Gs, Du Yj, Zhang Ys (2019) Feasibility of Device Closure for Multiple Atrial Septal Defects With an Inferior Sinus Venosus Defect: Procedural Planning Using Three-Dimensional Printed Models. Heart Lung Circ 19: 31361-31367.

Copyright: (C2020 Alvarez-Santana R. This is an open-access article distributed under the terms of the Creative Commons Attribution License, which permits unrestricted use, distribution, and reproduction in any medium, provided the original author and source are credited. 